\title{
Editorial
}

\section{¿Cómo liberarse de la corrupción?}

La corrupción es un hecho cotidiano en la sociedad salvadoreña. El presidente Calderón prometió en su primer discurso combatirla sin descanso. Tres años después, la corrupción sigue carcomiendo la institucionalidad del Estado y de la sociedad. La presencia mayoritaria de la oposición en la nueva asamblea legislativa ha colocado el tema en la lista de prioridades. De hecho, uno de los partidos políticos pequeños, cuya fundación es reciente, obtuvo dos curules en la nueva asamblea legislativa levantando la bandera del combate contra la corrupción. Los diputados de ARENA se han visto obligados a reconocer el fenómeno y la necesidad de luchar en su contra.

La oposición propone decretar nuevas leyes, reforzar las instituciones existentes relacionadas con el problema y crear otras nuevas y conformar una comisión para perseguir la corrupción. A otro nivel, el poder ejecutivo y la empresa privada plantean la privatización como el medio ideal para evitar la corrupción, asumiendo precipitadamente que en el sector privado ésta no tiene cabida. De aqui que sea oportuno discutir el problema planteado por una corrupción que se ha vuelto sistemárica y preguntarse por los medios más eficaces para liberarse de ella.

\section{El carácter sistemático de la corrupción}

El término corrupción admite una serie de precisiones conceptuales en las cuales no vamos a entrar aquí. Para el propósito de este editorial, entendemos por corrupción como el uso de la función o del cargo para fines contrarios a lo establecido por las leyes o normas. El catálogo de actos corruptos es amplio, pues incluye, entre otras cosas, el soborno, la extorsión, el tráfico de influencias, el nepotismo, el fraude y la malversación. Algunos de estos actos están tipificados como delitos en el código penal, pero otros no.

Por lo general, se tiende a pensar que la corrupción tiene lugar sólo en el sector público; pero la experiencia muestra que el sector privado está impli- 
cado en casi todos los actos de corrupción. Con frecuencia, la práctica corrupta ocurre en los puntos de contacto entre la esfera pública y la privada, cuando un funcionario monopoliza la distribución de un bien, un servicio o un beneficio valioso para un individuo o una empresa, y tiene la discrecionalidad para determinar quién lo va a recibir y en qué medida, o también cuando el Estado adquiere un bien o un servicio.

De aquí que algunos piensen de manera ingenua que reduciendo el tamaño del Estado también disminuyen las oportunidades para cometer actos corruptos. Es cierto que la llamada modernización del Estado, entendida en términos neoliberales, limita las posibilidades de corrupción, puesto que, de hecho, habrían menos contratos, permisos y subsidios, es decir, habrían menos oportunidades para que los funcionarios públicos pudiesen entablar relaciones con individuos y empresas privadas; pero nada de esto garantiza la erradicación de la práctica corrupta. Esta puede surgir con renovada intensidad en lugares donde ya había desaparecido o puede aparecer en otros nuevos. Por consiguiente, la reducción del Estado no garantiza por sí sola la desaparición de la corrupción, porque ésta puede cambiar de lugar con bastante facilidad, emigrando a otras relaciones o actividades.

El catálogo de actos corruptos es amplio, pues incluye, entre otras cosas, el soborno, la extorsión, el tráfico de influencias, el nepotismo, el fraude y la malversación. Algunos de estos actos están tipificados como delitos en el código penal, pero otros no.

Esto es así porque la práctica de la corrupción no sólo ocurre dentro del Estado, sino también en el sector privado y no pocas veces por incitación suya. El sector privado practica la corrupción cuando, para obtener ventajas sobre sus competidores actuales o potenciales, transgrede las leyes y normas impunemente. El afán por alcanzar el triunfo sobre los competidores se vuelve tan irresistible que no se presta atención a los costos humanos y materiales ni a los medios, lo cual incluye la práctica corrupta y a veces también el asesinato. Por lo tanto, la violencia no es ajena a una competencia convertida en un valor absoluto.

La privatización, una de las grandes soluciones neoliberales para reducir el tamaño del Estado y evitar la corrupción doméstica, proporciona un aliciente adicional para que los grandes consorcios internacionales compitan intensamente por los activos estatales más rentables de los pafses del sur. Así, contrario a lo esperado, en lugar de disminuir las oportunidades para las prácticas corruptas, éstas son mayores. 


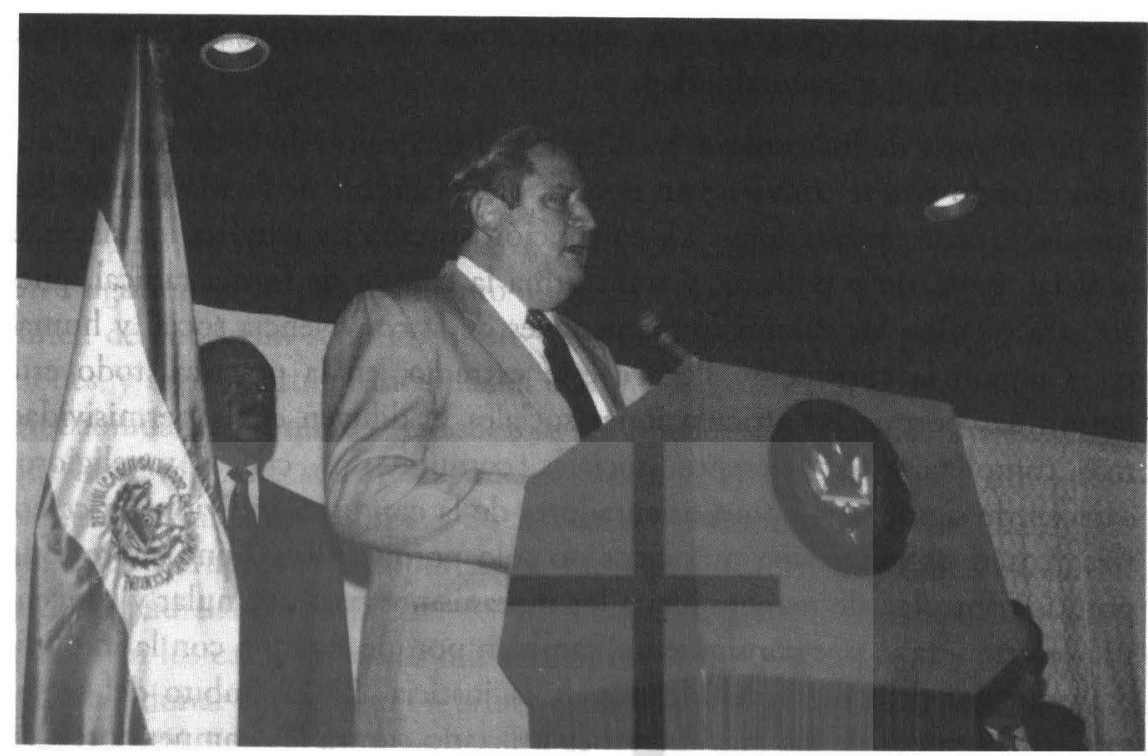

Las nuevas fuentes de riqueza y poder neoliberal, en particular determinados auges económicos, como los provocados por la privatización, el narcotráfico y la corrupción misma, han trastocado los valores sociales. La combinación de los valores de la sociedad consumista, cuyo objetivo fundamental era la riqueza, con los del neoliberalismo, cuya meta es el enriquecimiento fácil, incluso recurriendo a la acrividad ilegal o corrupta si es necesario, ha resultado devastadora para la sociedad y también para la comunidad internacional. Paradójicamente, esta extraña conjunción de valores neoliberales está respaldada por la cultura tradicional. Ya no se trata sólo de acumular riqueza, sino de conseguirla sin esfuerzo. La misma sociedad, quizás de manera inconsciente, promueve estos valores, al admirar y premiar a quienes consiguen enriquecerse con relativa facilidad, desconociendo que esto no es posible sin recurrir a actividades ilícitas e ilegales, a la violencia y al desprecio a la ley. De esta forma, pone como ejemplo del éxito empresarial e incluso de realización humana a quienes no respetan los valores que, por otro lado, reclama y añora.

La globalización neoliberal ha acentuado la competencia de los grandes consorcios internacionales por apoderarse de las riquezas de los países del sur. Es una competencia encarnizada que no conoce fronteras y que, en esa medida, ha extendido la corrupción a áreas hasta ahora libres. Por lo tanto, la corrupción no es exclusiva de los países del tercer mundo, cuya institucionalidad democrática es débil. Los paises con una tradición democrática sólida, que por otro lado, tampoco están libres de la corrupción, son los que más la promueven fuera de sus fronteras, pues no pocas veces recurren al soborno y la extorsión para hacer prevalecer sus intereses. Los grandes consorcios internacionales también practican la corrupción con cierta 
normalidad para desplazar a sus competidores, no obstante sus apariencias de respetabilidad y honorabilidad.

La mayoría de los sistemas sociales tolera una cierta dosis de corrupción, pero cuando ésta se convierte en norma, practicándose de forma sistemática, sus efectos son devastadores. La corrupción sistemática paraliza los sistemas judicial, bancario y político, y transforma la cultura de forma radical, pues arrastra consigo los valores fundamentales de la convivencia social y humana. Cuando la corrupción llega a este extremo, en la práctica, todo está permitido, porque las articulaciones sociales se diluyen en la permisividad más completa y los referentes sociales, comunitarios, cívicos y religiosos carecen de significado como orientadores de la conducta individual y colectiva. Los ricos se vuelven más ricos no sólo porque roban, sino sobre todo porque controlan de manera ilícita los mecanismos para acumular y concentrar esa riqueza y, por consiguiente, también porque cuentan con la impunidad, que los deja fuera del alcance de la justicia. En el ámbito del sector privado, el poder de los más fuertes es utilizado contra los competidores, en especial, contra los recién llegados. La lucha es encarnizada y sólo puede terminar con la eliminación de los contrarios. El discurso del mercado libre se esfuerza por encubrir esta dura realidad de la competencia capitalista, desatada en las últimas dos décadas.

la práctica de la corrupción no sólo ocurre dentro del Estado, sino también en el sector privado y no pocas veces por incitación suya.

Llamar la atención sobre la extensión y complejidad de la corrupción no debe llevar a concluir apresuradamente que ésta es algo inevitable contra la cual poco se puede hacer. Si éste fuera el caso, el conformismo fácil o la parálisis serían la reacción esperada. El llamado de atención pretende advertir contra el estereotipo cómodo y perjudicial, que no permite distinguir cuándo la corrupción se ha vuelto sistemática. Es evidente que toda la sociedad resulta perjudicada, en un momento u otro, de una u otra manera, y, por lo tanto, ella, como un todo, debe esforzarse por encontrar una salida.

\section{Prevenir la corrupción}

Existen medios eficaces para combatir la corrupción sistemática, superando al mismo tiempo la tentación del cinismo o la del fatalismo. Las respuestas tradicionales, como leyes nuevas más drásticas, controles más estrictos y el rescate de valores perdidos, resultan ineficaces si se consideran de manera aislada. La eficacia de las leyes y los controles depende de la existencia de instrumentos adecuados para aplicarlas con rigor. En teorla, los valo- 
res tradicionales pueden ser recuperados, pero para ello habrá que trabajar mucho y contra corriente, pues ni los gobernantes, ni los políticos ni mucho menos los empresarios se muestran interesados en ordenar sus prácticas de acuerdo con aquéllos.

El peso de la lucha contra la corrupción tampoco debe ponerse en la investigación y el procesamiento judicial, porque por lo general es muy difícil descubrir un soborno, sobre todo cuando éste es de grandes proporciones, y si por alguna casualidad el delito es descubierto, existen muy pocas probabilidades de que el responsable sea sancionado como se merece, porque los implicados se cuidan mucho para no dejar evidencia de sus operaciones fraudulentas. Eso para no hablar de la impunidad de la que suelen gozar los corruptos más importantes. En la práctica, es muy difícil encontrar pruebas judicialmente válidas de un soborno, tal como se ha podido comprobar en los casos de varios ministros del gobierno actual, quienes tuvieron que abandonar sus cargos, en el del director del Seguro Social y de la junta directiva del Fondo de Inversión Social. En las alcaldías, la corrupción no sólo ha sido rampante, sino que los alcaldes gozan de un fuero, expresamente concedido por los diputados de ARENA para ponerlos fuera del alcance de la justicia.

Cuando la corrupción ya es sistemática, la acción judicial contra el corrupto suele ser percibida como un azar. Las pruebas contra el imputado habrían sido encontradas por su mala suerte y no porque la policía estuviera interesada en la erradicación de la corrupción. No obstante estas deficiencias, conviene comenzar la lucha contra este mal social capturando a algu-

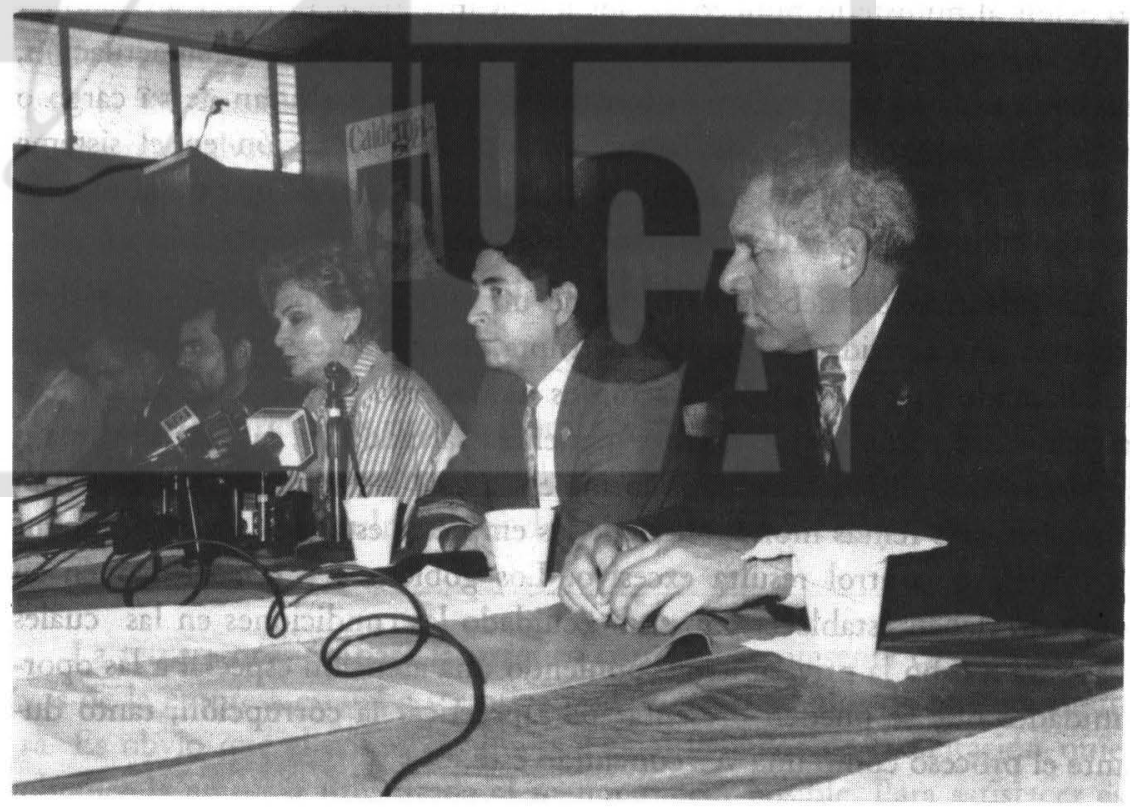


nos de los corruptos más grandes. En este caso, al igual que en el de los derechos humanos, la impunidad sólo puede ser rota condenando y sancionando a unos cuantos corruptos importantes. Más aún, para que la persecución no sea interpretada como una campaña contra la oposición, es recomendable empezar por aquellos corruptos importantes que militan en el partido oficial. Acciones de este tipo convencen a una población escéptica de la determinación del gobierno para acabar con la corrupción, puesto que cuando ésta es sistemática, aquélla no cree en las promesas gubernamentales ni en las de los políticos.

Una de las medidas más importantes para combatir la corrupción sistemática es la prevención. Pero para poder aplicarla con eficacia primero hay que identificar las áreas donde aquélla se practica con mayor frecuencia. No se trata, pues, de prevenir en general, sino de ejercer controles preventivos ahí donde se sabe de antemano que se practica la corrupción en gran escala. La prevención supone reforzar institucionalmente los puntos vulnerables de la estructura social y estatal. Más en concreto, para disminuir la corrupción es indispensable limitar o regular los monopolios de forma cuidadosa, delimitar de manera estricta la discrecionalidad de los funcionarios públicos, reforzar los mecanismos para capturar, procesar y sancionar judicialmente a los corruptos, abarcando tanto a quien incita como a quien accede.

Incluso la acción judicial ejemplarizante contra el corrupto exige la prevención por dos razones. Primera, para corregir la percepción de que aquélla es un simple resultado de la casualidad o la mala suerte y segunda, porque si la sanción judicial es entendida como el último recurso del control social, sólo debe aplicarse para confirmar la vigencia de las normas. Es contradictorio exigir al ministerio público y a los jueces investigar, procesar y sancionar a los corruptos, cuando el poder ejecutivo no sólo no previene su actuación, sino que además la promueve, protegiendo a quienes abusan de su cargo o poder. Descargar el peso de la lucha contra la corrupción en el sistema judicial es encubrir la responsabilidad del poder ejecutivo, que nombra a los funcionarios públicos y debe controlarlos.

La privatización debe ser objeto de un cuidado especial, porque si se privatiza una actividad o empresa corrupta, lo que antes era soborno ahora será llamado precio. La privatización es un proceso privilegiado para la corrupción, tal como lo prueba la experiencia salvadorefía, la cual se suma a muchas otras, pues determina la forma en la cual los licitantes y el gobierno se reparten las rentas monopólicas de las empresas estatales. Por eso, ninguna cautela o control resulta excesivo. Los gobiernos y la sociedad en su conjunto deben establecer con sumo cuidado las condiciones en las cuales se llevará a cabo la privatización, poniendo una atención especial a las oportunidades que se pueden presentar para practicar la corrupción, tanto durante el proceso como una vez concluido éste. 
La primera gran oportunidad se da al elaborar la lista de los licitantes precalificados. Es común que algunos consorcios internacionales sobornen para ser incluidos o para que el número de licitantes potenciales sea reducido, lo cual aumenta sus posibilidades. La supervisión del proceso por parte de otras compafías internacionales no ofrece garantías sólidas de integridad, porque éstas suelen estar relacionadas con aquellas que aspiran a ser incluidas en la lista de precalificación.

Otra oportunidad importante para la corrupción se presenta cuando las normas que regulan el proceso son imprecisas. En efecto, las imprecisiones abren la puerta a una serie de irregularidades, como proporcionar a los corruptos información no disponible al público o entregarles información de manera anticipada, u otorgar a las empresas corruptas un tratamiento especial. La falta de claridad sobre el régimen tributario y las regulaciones a las cuales quedarán sujetas las empresas privatizadas al concluir la transacción también se presta a prácticas corruptas. No es extraño que los licitantes corruptos puedan buscar asegurarse la permisividad del control fiscalizador del Estado. Todo ello a cambio de comisiones jugosas. En los casos de corrupción extrema no existe licitación alguna, pues la empresa estatal se otorga al consorcio internacional con la mejor conexión política.

Para evitar estos abusos, las normas que rigen el proceso de privatización y el desenvolvimiento de la empresa ya privatizada deben ser fijadas de forma creíble y clara antes de que aquél comience. Las leyes sobre el conflicto de intereses, que intentan impedir al funcionario público obtener ventajas de su posición privilegiada, por lo general sólo representan un inconveniente para los poderosos intereses de quienes se benefician directamente del soborno. Las medidas preventivas a este nivel reducen la incertidumbre asociada a cualquier licitación y la posibilidad de que el licitante ganador manipule la fiscalización posterior. Por eso, la derogación de la ley para privatizar la empresa salvadoreña de telecomunicaciones por parte de los diputados de la oposición está justificada plenamente. Más aún, ninguna cautela para impedir que el proceso de privatización se vuelva una oportunidad para la práctica corrupta está de más, dada la voracidad del capitalismo neoliberal.

Una de las medidas más importantes para combatir la corrupción sistemática es la prevención, que supone reforzar institucionalmente los puntos vulnerables de la estructura social y estatal.

La tercera ocasión para la práctica corrupta se presenta cuando los activos de la empresa estatal a ser privatizada no son tasados de manera rigurosa. Es obvio que el consorcio internacional ganador de la licitación quiera obtener la empresa privatizada al menor precio posible. Para satisfacer este 
interés, hasta cierto punto legítimo, el funcionario corrupto, apoyado en datos aparentemente fidedignos, suele informar a la opinión pública que la empresa que va a ser privatizada o vendida se encuentra en crisis; pero a los consorcios favorecidos les proporciona la información real, en la cual se muestra su rentabilidad. Esta información permite que los consorcios internacionales corruptos sean los grandes licitantes, en lo que aparenta ser una licitación limpia y abierta. Más tarde, las altas tasas de rendimiento de la empresa vendida son difundidas profusamente para demostrar el éxito de la privatización.

Desde esta perspectiva, la venta de la empresa de telecomunicaciones salvadoreña es un buen ejemplo de lo que no se debiera permitir. El valor real de sus activos se desconoce, aunque se sabe de la existencia de varios valúos. La propaganda gubernamental intenta convencer a la opinión pública que si la empresa no es privatizada no podrá satisfacer la demanda, ni adquirir la nueva tecnología, enfrentando en el corto plazo la posibilidad de una quiebra. En realidad, el plan de inversión y modernización de la empresa fue detenido por orden superior hace varios ańos para generar la impresión de crisis. Se rechazaron créditos blandos para invertir, se adquirió equipo moderno al cual no se le da uso, no se han conectado centenares de líneas que podrían satisfacer parte de la demanda y generar ingresos y se desconoce su rentabilidad aun con estas limitaciones. Tampoco existe claridad sobre cuál será el destino del producto de la venta.

La cuota de poder monopólico que la empresa ya privatizada pueda retener de la antigua empresa estatal es otra oportunidad para la corrupción. Por eso, el funcionario público, en nombre del Estado, y el licitante intentan retener una parte de ese poder. Para el primero, que el Estado conserve una cuota de su antiguo poder monopólico representa una oportunidad segura para captar sobornos. Para el licitante, la retención de tal poder también es importante, porque el valor de la empresa ya privatizada aumenta en relación directa con dicha cuota de poder. Sin embargo, las rentas monopólicas contradicen la justificación teórica de la privatización. Un gobierno que confiesa los principios de la competencia, no puede apoyar de forma abierta el monopolio. Para salvar esta dificultad, tanto la empresa como el funcionario recurren a la transacción corrupta, utilizando canales ocultos. De esta manera, la privatización de los monopolios estatales ofrece oportunidades únicas para obtener ganancias extraordinarias, tal como ha quedado demostrado hasta la saciedad en el caso de El Salvador.

Ahora bien, éstas no son todas las oportunidades que un proceso de privatización ofrece para la práctica corrupta. Se privatiza para apartar al funcionario público de una tentación, de hecho, irresistible; pero se supone que a partir de aquélla, la empresa operará sujeta a la disciplina del mercado y ajena a la corrupción. La experiencia demuestra que este supuesto carece 


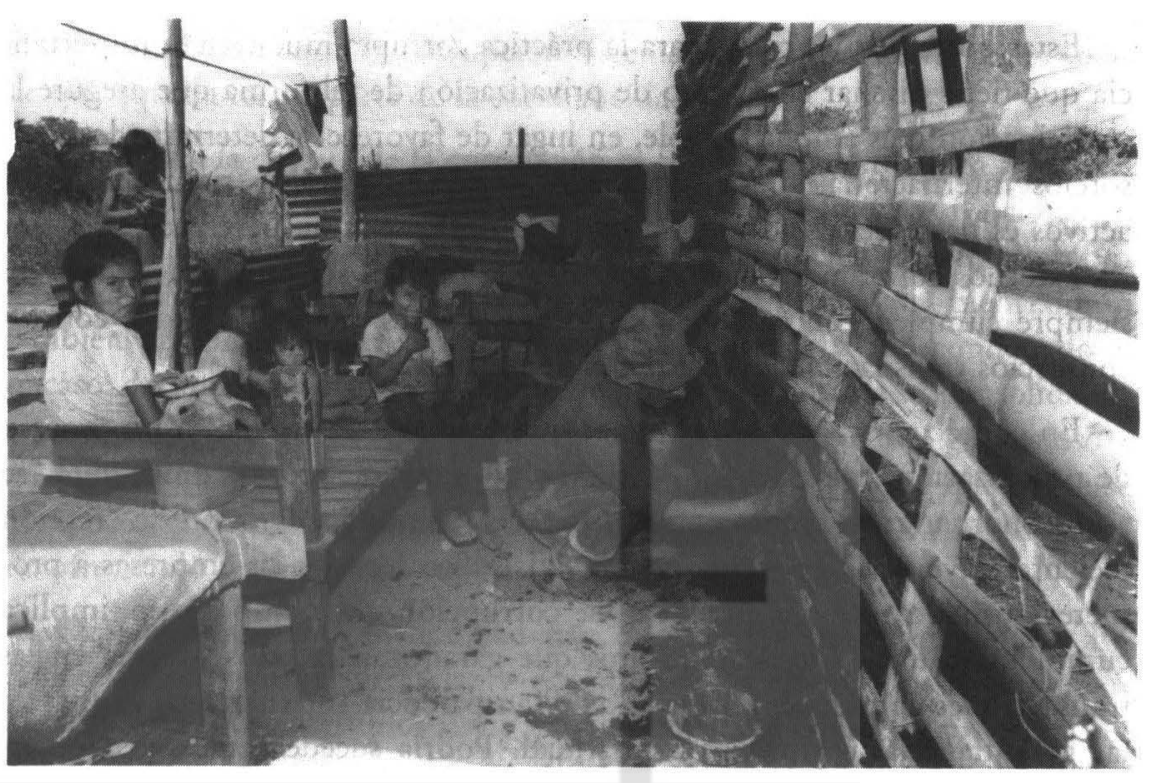

de fundamento real, porque el sector privado también la practica sin reparos económicos y morales.

En la medida en que una empresa privatizada conserve una cuota del poder monopólico estatal estará obligada a mantener una relación estrecha con el gobierno. De hecho, esto es casi inevitable, dado que, por lo general, las empresas públicas se encuentran en industrias con economías de escala considerables y en áreas de interés nacional, como los servicios y el transporte. Pero éstas no son más que nuevas oportunidades para la corrupción. Por ejemplo, a veces el contrato de privatización establece que el gobierno vuelva a negociar con la empresa al cabo de unos pocos años, lo cual puede ser una buena estrategia, si permite aumentar la competencia, pero también puede ser ocasión para nuevas negociaciones corruptas. Puede suceder también que la tarifa de los servicios prestados por la empresa privatizada deba ser aprobada por el Estado, lo cual, si no se toman la cautelas necesarias, es otra oportunidad para que la empresa y el funcionario hagan transacciones corruptas a costa del consumidor.

En aquellos casos en los cuales el gobierno no vende o privatiza toda la empresa, sino que se reserva una parte sobre la cual ejerce control, el arreglo corrupto se da con relativa facilidad. El sector privado puede intentar pasar las pérdidas al Estado con la connivencia de los funcionarios públicos o puede continuar siendo objeto de trato especial, recibiendo privilegios, por parte de aquél. Por eso, en cuanto se presenta la posibilidad para la negociación interna, la privatización debe ser aplazada, pues es más fácil supervisar una empresa estatal que una privada. 
Estas posibilidades reales para la práctica corrupta muestran la importancia que tiene diseñar el proceso de privatización de tal forma que asegure la participación más amplia posible, en lugar de favorecer a determinados consorcios internacionales y a sus aliados locales. $\mathrm{El}$ avalúo riguroso de los activos es parte del esfuerzo para que el proceso sea transparente. Los asesores externos contratados para cuidar de ella pueden ser muy útiles, pero no siempre cumplen con su función, porque a veces están vinculados con los consorcios transnacionales que pretenden licitar.

En consecuencia, a los consorcios que aspiren a participar en un proceso de privatización se les debería exigir como requisito previo comprometerse a no sobornar ante Transparencia Internacional, una asociación de creación reciente, cuyo objetivo fundamental consiste en forzar a las empresas a prometer formalmente no practicar la corrupción. El compromiso implica cumplir con una serie de requisitos que garantizan la transparencia en las transacciones comerciales. El aval de Transparencia Internacional es una de las garantías más seguras de honestidad. Podría suceder que este requerimiento redujera el número de licitantes, pero la eliminación de los consorcios corruptos no disminuirá la competitividad, sino que, al contrario, la aumentará. Los consorcios internacionales, por su lado, deben comprender que son parte del problema y también de su solución. El gerente más eficiente puede ser derrotado con facilidad por un corrupto.

\section{La participación de la sociedad}

Tan importante como la prevención es incluir a la sociedad en el combate contra la corrupción sistemática, dándole un papel activo. El presupuesto de esta medida es que muchos de quienes pagan sobornos preferirían no hacerlo, por lo tanto, si se les otorgasen las garantías necesarias, estarían dispuestos a denunciar las prácticas corruptas. Pero para ello, antes es indispensable romper con la cultura de la corrupción. El éxito depende del compromiso conjunto del gobierno y de la sociedad. El primero debe demostrar que está decidido a luchar contra la corrupción sistemática, procesando judicialmente a los corruptos más conocidos, estimulando a la sociedad a participar y fortaleciendo la institucionalidad del Estado. Aquélla, por su parte, debe asumir el reto y volverse parte activa de la solución. No debe continuar aceptando de forma pasiva la cultura de la corrupción. Sería contradictorio que mientras condena el soborno, se aviniera a pagarlo sin reaccionar de manera positiva.

En la medida en que la sociedad percibe la corrupción como un hecho ordinario, actúa como cómplice del corrupto, cerrando el clrculo y dando paso a la cultura de la corrupción. El ciudadano espera que el funcionario actúe de una manera determinada y, en consecuencia, le ofrece el soborno de forma voluntaria y no opone resistencia a la coacción para guardar silen- 
cio. El combate contra la corrupción sistemática exige desterrar la creencia de que aquélla forma parte de la cotidianeidad.

En efecto, la cultura de la corrupción se fundamenta en la idea de que la corrupción es algo común y generalizado. Supone que los altos funcionarios también la practican. Cuando la sociedad cree que quienes tienen la responsabilidad formal de actuar contra los corruptos y a favor del bien común también practican la corrupción, el combate contra ésta está condenado al fracaso de antemano. En la medida en que esa cultura se consolida, la resistencia individual pierde sentido, pues se presenta como algo costoso e inútil. Entonces, el ciudadano no encuentra otra alternativa que volverse cómplice del corrupto y así sus prácticas contribuyen a consolidar esa cultura, ofreciendo o admitiendo sobornos de forma voluntaria.

Para modificar esta mentalidad hay que sacudir sus fundamentos. En esto el gobierno debe ser audaz y estimular a los ciudadanos a participar, identificando a los corruptos y sus prácticas. En este contexto, procesar con mucha publicidad a algunas personalidades corruptas relevantes del sector privado, incluyendo a empresarios nacionales y extranjeros, políticos del partido oficial, magistrados y jueces, y también a burócratas puede resultar estimulante para la sociedad. Este enfoque es más eficaz para atacar la cultura de la corrupción que conformarse con decretar leyes más duras o contar con más y mejores policías.

Tan importante como la prevención es incluir a la sociedad en el combate contra la corrupción sistemática, dándole un papel activo.

La participación activa de los ciudadanos es determinante, dado que nadie mejor que ellos saben dónde están los corruptos y cómo operan. El ciudadano común y corriente entiende perfectamente bien cómo el soborno determina el tipo de servicio que recibe. En particular es transcendental la colaboración de los abogados, quienes entienden mejor que cualquiera el funcionamiento corrupto del sistema judicial; los contadores y auditores, quienes conocen cómo se ejecutan y ocultan las operaciones y transacciones fraudulentas, y los comerciantes y empresarios, quienes suelen estar familiarizados con las prácticas corruptas usuales en la contratación de los servicios y suministros. Esta colaboración crucial sólo será posible si los ciudadanos están convencidos de que es posible liberar a la sociedad de los corruptos y si el gobierno les abre los espacios necesarios para denunciarlos.

Ahora bien, no se trata tanto de lanzar una cacería de brujas, persiguiendo a individuos o empresas corruptas en particular -aunque esto tiene su 
importancia para convencer a la población de la seriedad del compromiso gubernamental con una sociedad libre de corruptos-, como de entender el funcionamiento de la corrupción en la estructura social. Si sólo se persiguen corruptos, por muy espectacular y ejemplarizante que ello resulte, dejando intacto el sistema que les permite operar, muy probablemente, las prácticas corruptas persistirán.

Los casos individuales de corrupción deben ser perseguidos como parte de una estrategia más amplia que busca una reforma institucional que dificulte la practica de la corrupción. Hay que pasar, pues, de la denuncia al entendimiento de la estructura social para luego reforzar sus puntos más vulnerables. Desde esta perspectiva, no vale la pena concentrar el esfuerzo en la permisividad o la decadencia social. Es más eficaz concentrarse en la lógica económica de la cultura de la corrupción y en las medidas para contrarrestarla. Sólo la acción colectiva y una reforma creíble y sistemática de la institucionalidad de la nación pueden liberar a la sociedad de la corrupción. El esfuerzo no debe dirigirse a cualquier parte de la estructura social, sino a aquellas donde se sabe de antemano que se practica la corrupción en gran escala. Sin duda, la acción bien dirigida impactará la sociedad de una forma positiva.

Así como a nivel mundial existe Transparencia Internacional, a nivel local se podrían establecer comités civiles, para vigilar a quienes prestan servicios públicos e investigar de forma independiente las denuncias de soborno. En esta misma línea, el gobierno podría exigir que las empresas interesadas en participar en la licitación de sus contratos firmaran antes una declaración, comprometiéndose a no sobornar. Al mismo tiempo, debiera establecer una instancia de alto nivel, encargada de la coordinación de su estrategia contra la corrupción. De ella no sólo debieran formar parte la policía, el ministerio público, la contraloría y los jueces, sino también los ciudadanos. Para romper el círculo vicioso de la práctica corrupta es muy importante difundir los resultados de las investigaciones. En este contexto, los medios de comunicación social tienen un papel insustituible.

La cultura de la corrupción se fundamenta en la idea de que la corrupción es algo común y generalizado.

Parte importante de la reforma institucional necesaria, orientada a un ejercicio del poder ajustado al derecho y la equidad, son los incentivos. No es realista esperar que polićas, fiscales y jueces mal pagados rechacen sobornos elevados, cuando las probabilidades de que los descubran son prácticamente nulas y si por acaso los llegasen a descubrir, la sanción sería leve o inexistente. Con demasiada frecuencia, los salarios del sector público son tan bajos que no permiten que una familia pueda vivir con el ingreso pro- 
medio de un funcionario. Por otro lado, el salario de los funcionarios públicos no está relacionado con lo que producen, pues no se acostumbra la evaluación sistemática.

Los incentivos deben orientarse a recompensar el desempeño honesto y los logros en la lucha contra la corrupción. Simultáneamente, las sanciones para los transgresores deben ser más drásticas. Se podría objetar que los incentivos implican elevar aún más el gasto público, a lo cual se puede responder que con frecuencia se gastan sumas enormes en combatir la corrupción sin conseguir resultados significativos, por carecer de una estrategia adecuada. Otra de las medidas más socorridas consiste en aumentar los controles y ampliar la burocracia, elevando el gasto público, pero sin mejorar la eficiencia. Eso para no hablar del elevado costo que la corrupción sistemática representa para la actividad económica ni del obstáculo que supone para mejorar las condiciones de vida de la población y avanzar en la modernización del Estado y la sociedad.

Aquí es donde la revisión de la legislación vigente cobra su importancia, en particular la ampliación de la evidencia judicial admisible en los casos de corrupción y la imposición de sanciones bastante más drásticas para los corruptos sancionados. Para que este esfuerzo legislativo redunde en eficacia, debe ser considerado como parte de una estrategia contra la corrupción y no como un instrumento aislado. La lucha contra la corrupción debe ser concebida como parte de un esfuerzo nacional por liberar a la sociedad de uno de los males más destructivos.

San Salvador, 14 de junio de 1997. 